\title{
Pandemic as a factor in adjusting the methodology of indicative planning for the implementation of the region's innovation policy
}

\author{
Tatyana Ladykova ${ }^{1, *}$, Ivan Danilov ${ }^{1}$ \\ ${ }^{1}$ Chuvash State University, 15, Moskovsky prospect, 428015, Cheboksary, Russia
}

\begin{abstract}
The purpose of the article is to identify the consequences of the coronavirus pandemic on economic growth, as well as ways to overcome its negative consequences based on innovation and digitalization of socioeconomic processes. The look at pandemic of the coronavirus as at a kind of Schumpeterian "creative destroyer", implies the necessitates of expanding the interpretation of innovation not only as a result of human activity, but also the activity of the biosphere, one of the components of which are humans and viruses. The pandemic has updated the issues of planning and forecasting in modern socio-economic systems, especially indicative planning. In order to overcome the negative consequences of the coronavirus pandemic COVID-19 and other unforeseen factors of a radical nature, federal and region powers use the tools of indicative planning within region's innovation policy.
\end{abstract}

\section{Introduction}

In modern conditions of digital transformation of socio-economic relations (digital revolution 4.0), innovation covers all areas. In this case, not separate innovations arise, but their interconnected complex in informatics, nanotechnology, microelectronics, artificial intelligence (AI), cyber-physical systems that unite individuals, information, computer technologies, the Internet of things, digital enterprises, smart cities, etc. Currently, innovations affect all aspects of socio-economic activity and act as powerful catalysts for the development of the entire human civilization.

Within the framework of the public administration system, the effectiveness of forecasting, strategic, indicative and tactical planning is increasing, in particular through the use of Big Data, as well as tools for their analytical processing, neural network technologies, etc.

Digitalization transforms innovation processes, reduces the cost of production, promotes the implementation of such innovations that are at the intersection of industry and service, and also lead to the acceleration of innovation cycles. However, data makes the greatest contribution to modern innovation, and many innovations are embodied in software. All this has an impact on the processes of state support for innovation. In particular, it is

* Corresponding author: ladykova@mail.ru 
required to ensure wide access of business structures to various arrays of information, which in many countries is implemented in the form of a policy of open (free) data [1].

\section{Applied methodology. Literature review}

The data for the proposed research were materials of international organizations, publications in Russian and foreign scientific and periodicals official materials of government agencies.

In 2002, SARS caused SARS coronavirus unexpectedly and widespread in China. Its mortality rate was $10.9 \%$ (the ratio of the number of infected to deaths). Due to the use of quarantine measures, there has been a significant violation of international communications. In 2012, the Middle East respiratory syndrome coronavirus (MERS-CoV, MERS-CoV) appeared, which by 2015 had been detected in 26 countries. Moreover, its mortality rate was $35.7 \%$, and patients often contracted it in hospitals [2].

The pandemic of the coronavirus COVID-19 in 2020 acted as a powerful factor of Schumpeterian "creative destruction" or the process of economic mutation, which continuously revolutionizes the economic structure from the inside, destroying the old structure and creating a new one [3], i.e. it itself has led to significant destruction in socioeconomic systems. In this aspect, in our opinion, the position that obsolete industries should not be preserved indefinitely remains relevant, but we must try to avoid collapse and turn the chaos, which can generate a cumulative reaction in the entire economy, into an orderly retreat [3] ... At the same time, scientific thought is constantly developing and the historical analysis of the evolution of the concept of "innovation" $[4,5,6]$ and the trajectories of innovation processes [7] can allow to outline new approaches to the analysis and synthesis of the main components of innovation processes, both transforming and experiencing significant external impact of the results and consequences of the pandemic.

Innovation can also reduce the severity of a range of social problems stemming from deficiencies, such as health systems or education. For example, a number of them are aimed at maintaining the physical and social activity of older people.

At the same time, like any socio-economic phenomenon, innovations also have negative potentials, the uncontrolled implementation of which can and does lead to the emergence of new problems and challenges, acting as a factor that increases uncertainty [8]. Therefore, such innovations are required that will contribute to sustainable development at the mega, macro and meso levels (world, country and region) [9]. Sustainable development implies taking into account environmental factors in the process of innovation [10], and this, in turn, requires inclusion of epidemics and pandemics into the environmental factor, with appropriate forecasting and planning at the state level.

The COVID-19 coronavirus pandemic has led to the expansion of the digitalization sphere, which within enterprises is increasing its scope of use in the processes of production, supply, sales, etc. The main imperative of this process is to ensure the growth of profitability, profitability, and labor productivity. Business transformation is taking place in many industries, as a result of which the preconditions for the creation of new enterprises, jobs, etc. are emerging. The pandemic has also stimulated the development of digital platforms, in particular, in trade, transport, education, healthcare, etc.

To assess the impact of the pandemic on indicative planning of innovation processes, we formulate the following main fundamental economic problem, which we will consider in this article: How does innovation affect economic growth, taking into account the factor of the COVID-19 pandemic, as well as the risks of their occurrence in the future?

An analysis in the pre-pandemic period of such Eastern European countries as Montenegro, Serbia, Russia, the Czech Republic, Poland and Hungary revealed a significant correlation between the characteristics of countries' competitiveness in terms of 
GDP per capita, higher education and innovation. The correlation between higher education and GDP was significant for Poland, Czech Republic, Russia, and Hungary, while the correlation between innovation and GDP was significant in Serbia, Poland and Hungary. A significant correlation between higher education and innovation was noted only in Russia [11].

However, in Poland, industrial companies have most often introduced new or significantly improved products, while service companies have introduced new or significantly improved methods of division of tasks, decision-making powers or human capital management. More than half of the non-innovative businesses were classified in the transport and warehouse management industry. The smallest percentage of such enterprises were related to the production and supply of electricity, gas, steam, hot water and air for air conditioning systems. Most of the non-innovative companies implemented core business functions mainly within themselves [12].

At the same time, it was noted that the priorities of growth and development should be associated, firstly, with the objects of innovative transformation, secondly, with the preferences of the main economic agents and, thirdly, with external and internal conditions, factors, as well as the dynamics of changes within country [13].

In addition, the analysis of the main indicators characterizing the innovation activity of the BRICS countries showed that, despite the positive dynamics of growth in the absolute costs of science to GDP, the BRICS countries lag significantly behind the developed countries. Trade, economic, scientific and technological interaction between the BRICS countries, as before, accounts for an insignificant share in comparison with the volume of their trade with the EU and the USA. At the same time, the growth of patent activity and publications are gradually beginning to reduce their gap with developed countries (the highest growth dynamics is in China, followed by Russia) [14].

\section{Discussion}

The main hypothesis that we will consider in this article can be formulated as follows - the COVID-19 coronavirus pandemic has increased the positive impact of innovation, especially digital, on economic growth. Here we can note the fact that digital innovations and the explosive expansion of the scope of their use in the context of a pandemic made it possible to reduce the magnitude of the economic recession both in many industries and in the socio-economic system as a whole. For example, without online commerce and delivery services, sales of many goods would approach zero, without remote work, the activities of many enterprises would be frozen, without distance education, both the education system itself and the students, especially young people, would experience more serious problems with the processes. training, etc.

Therefore, one of the criteria for the effectiveness of a particular innovation may be the ability to ensure growth in normal and pandemic conditions or a slight decrease in this indicator in pandemic conditions.

Schumpeterian "creative" destruction has taken place, for example, in tourism. Quarantine measures caused by the pandemic quite logically led to the fact that people stopped moving both between countries and within countries and settlements. Even after the quarantine was lifted, a number of restrictions remain, preventing tourist flows from recovering in their previous volumes. Thus, tourism as a sector of the economy will go through a period of global innovative transformations associated with significant changes in the structure of demand for tourism services, depending on their types and directions.

The development of domestic tourism acts as the main directions in the context of continuing restrictions on the movement of citizens between countries. At the same time, the desire of many people to get acquainted with the specific features of other countries will 
not go anywhere, and here there will be a partial replacement of the physical presence of a person in one or another point of the globe with a virtual one. New companies will appear on the tourism services market that will develop digitalization of tourism using virtual reality technologies, expanding not only its visual component, but also tactile, tactile, olfactory, etc. These technologies existed before the pandemic, and its consequences will stimulate the expansion of their sphere use.

The tourist of the future will not need to be physically present, for example, in Venice, because being in his own apartment, he will be able to immerse himself in such a virtual reality, in which he will experience the corresponding sensations as during a boat ride on a gondola: historical buildings will float past, sway on the waves will be felt, the specific smell of water will be smelled, and hands will feel a paddle, etc. .d. And all this without the risk of contracting any new disease.

Numerous facts of the explosive growth in popularity of virtual visits to museums, art galleries, concerts, etc. testify to this virtual tourism destination. In a pandemic, this often happened haphazardly, spontaneously and free of charge. But at the same time, using the already existing developments in the field of marketing and monetization of virtual services, it can be assumed that those social and cultural leisure organizations, for example, museums, art galleries and other objects of this kind, which will digitize their funds as much as possible, will be able to make money by offering, in addition to free virtual services, paid ones.

By developing virtual tourism, digital companies will be able to offer buyers new types of it, in principle unattainable in real life for the average tourist, for example, diving to the bottom of Lake Baikal or the Mariana Trench, walking with a shark or whale, traveling to the center of the Earth, flying followed by a walk on the Moon, Mars, Saturn, Jupiter and other planets of the solar system, as well as other star systems.

The next direction of tourism transformation is maximum protection, which very often implies individualized tourism.

The COVID-19 coronavirus pandemic has shown that computer technology is also actively used in biotechnology. Innovations are created in the field of a certain transformation of both individual biological objects, for example, viruses, bacteria, etc., and the use of genetic editing technologies. A powerful innovative upsurge is taking place in health care, medicine, biology, such innovative areas as bioinformatics, genetic engineering, etc. have developed rapidly.

At the same time, taking into account the development of synthetic biology and information technologies, there are risks of unlawful interference in the processes of laboratory DNA synthesis and the production of living unicellular organisms with specified properties, mainly for the purpose of producing substances that are safe and useful for humans and animals. The purpose of the intervention can also be a deliberate distortion of the DNA nucleotide sequence up to the latent introduction of genome regions of pathogens of the I group of pathogenicity, which can lead to the acquisition of pathogenic properties by a new organism with a high potential for uncontrolled spread [15].

The pandemic not only caused the expansion of the scope of many innovations or the emergence of new ones, but itself was a kind of "creative destroyer". And in this regard, in our opinion, requires a rethinking of the theoretical and methodological content of the category "innovation". In particular, Prigozhin A.I. a classification of innovations was proposed, which should be the carrier of the following main characteristics: the sphere of distribution, position in a particular production process, continuity, predicted market share, degree of novelty [16, p.81].

The analysis shows that the pandemic and the socio-economic consequences caused by it, almost instantly, by historical standards, covered the entire world economy and human civilization. It became a logical continuation of the development of a number of infections 
in a socioeconomic, not virological context. And besides, it can serve as a definite marker or basis for subsequent pandemics. Directly or indirectly, it began to be present in one form or another in many production processes. The industries most affected by the pandemic are passenger transportation, especially aviation, the service sector, trade, especially concentrated in large shopping centers, etc.

The COVID-19 coronavirus pandemic in some industries, such as tourism or air travel, has captured significant market shares, and innovative digital solutions in these conditions have the potential to significantly redistribute in their favor many markets for digital companies. Although infections and pandemics themselves are not something new for humanity, the COVID-19 coronavirus pandemic is a completely new phenomenon, for which humanity, countries and many economic actors turned out to be completely unprepared.

The innovative potential of the pandemic can be characterized as very high, due to the fact that a number of existing digital solutions have increased the scope of their use, as well as a number of completely new innovations have appeared, the number of which will increase as the consequences of the pandemic are analyzed in terms of reducing its negative consequences. In the theory of innovative development itself, one of the powerful sources is a crisis in one form or another. The pandemic of the coronavirus COVID-19, considered in the socio-economic aspect, as well as the consequences caused by it, was a similar source and those countries and economic entities that are aware of this circumstance will receive significant benefits and vice versa.

In the theoretical and methodological aspect, it was assumed that innovations are the result of a scientific discovery, invention or technical achievement, implemented in a certain commercial product [8]. The pandemic of the coronavirus COVID-19, in our opinion, acted as an objective factor in favor of expanding the interpretation of innovation not only as a result of human activity, but also the activity of the biosphere [17], one of the components of which are humans and viruses.

From the standpoint of an innovative approach, it is possible to predict and plan the emergence of new goods and services that will allow economic entities to reduce (maintain) costs, increase (maintain) labor productivity and profitability not only in a growing or stagnating economy, but also in a global quarantine that has strengthened the economic recession. Research conducted to combat the COVID-19 coronavirus itself and its consequences will lead to radical innovation. In this innovative context, the pandemic acted as a kind of negative catalyst that accelerated scientific and technological progress in many areas.

The next global innovation, triggered by the COVID-19 coronavirus pandemic, is the so-called "coronation" of economic activity, which is the antipode of globalization. Moreover, this innovation is cyclical, each time reviving at a qualitatively new level and basis. If US President Donald Trump seeks to "nationalize" the American economy, i.e. focused on the development of the domestic market and American manufacturers, then one of the global consequences of the pandemic is China's turn in the same intra-Chinese direction. Thus, the two largest economies in the world are drifting towards the priority development of their own markets and economic entities. Similar processes will occur in other countries based on the analysis of the socio-economic consequences of the pandemic.

As a result of the pandemic, the entire world economy and the economies of all countries showed an economic decline (negative economic growth), many authoritative experts and international organizations predict a decrease in GDP in 2020 compared to the pre-pandemic 2019.

The pandemic and the necessary containment measures used to limit its spread have resulted in the closure of large, medium and small businesses and entire sectors around the world, causing dramatic and sudden cuts in production, costs and employment. According 
to experts from the OECD (Organization for Economic Development and Cooperation), in the first quarter of 2020, world GDP contracted by about $3 \%$, although measures to contain and mitigate the consequences in many countries were introduced only in early March. Activity fell sharply in China, the initial center of the pandemic, where production was down 10\% from Q4 2019. Other Asian countries with strong ties to China and significant tourist flows also saw production declines. In developed European countries, the decline in production was more significant than in the United States or Japan, reflecting earlier and more stringent quarantine measures that led to a halt in production. [18].

The IMF in Europe predicts a decline in GDP in 2020 by $6.6 \%$ and its growth by $4.5 \%$ in 2021 (in 2019, this indicator increased by 1.6\%). At the same time, the largest decline in GDP in 2020 is expected in San Marino - 12.2\%, the smallest - in Malta - 2.8\%. In this aspect, several clusters can be distinguished, depending on the degree of decline in the GDP level. 1 cluster (down to 5.0\%). This group includes such countries as Malta (2.8\%), Serbia $(3.0 \%)$, Hungary (3.1\%), Bulgaria (4.0\%), Poland (4.6\%), Luxembourg (4, 9\%), Turkey $(5.0 \%)$ and Romania $(5.0 \%)$.

Cluster 2 (decrease 5.1-7.0\%). This cluster includes Russia (5.5\%), Belarus (6.0\%), Switzerland (6.0\%), Finland (6.0\%), Norway (6.3\%), Great Britain (6.5\%), Denmark (6.5\%), Cyprus (6.5\%), Czech Republic (6.5\%), Ireland (6.8\%), Slovakia (6.8\%), Sweden (6.8\%), Belgium (6.9\%), Germany (7.0\%) and Austria (7.0\%).

Cluster 3 (decrease $7.1-9.0 \%$ ). There are such countries as Iceland (7.2\%), France (7.2\%), Estonia (7.5\%), Ukraine (7.7\%), Spain (8.0\%), Portugal $(8.0 \%)$, Slovenia $(8.0 \%)$, Lithuania (8.1\%), Latvia $(8.6 \%)$ and Croatia $(9.0 \%)$.

4 cluster (more than $9.0 \%$ decrease). This group of countries includes Italy $(9.1 \%)$, Greece (10.0\%) and San Marino (12.2\%).

In 2021, GDP growth is projected in all European countries. In terms of growth rates, the following main clusters can be distinguished. Group 1 (up to $4.0 \%$ ), which includes such countries as Norway $(2.9 \%)$, the Netherlands (3.0\%), Finland (3.1\%), Belarus $(3.5 \%)$, Russia (3.5\%), Ukraine (3.6\%), Switzerland (3.8\%), Romania (3.9\%), Great Britain (4.0\%).

Group 2 (4.1-6.0\%). This group includes Hungary (4.2\%), Spain (4.3\%), Austria (4.5\%), France (4.5\%), Belgium (4.6\%), Italy (4.8\%)), Luxembourg (4.8\%), Croatia (4.9\%), Portugal (5.0\%), Slovakia (5.0\%), Turkey (5.0\%), Greece (5.1\%), Germany $(5.2 \%)$, Sweden (5.2\%), San Marino (5.4\%), Slovenia (5.4\%), Cyprus (5.6\%), Bulgaria (6.0\%), Denmark (6.0\%), Iceland (6.0\%).

Group 3 (more than $6.0 \%$ ). This group of countries includes Ireland (6.3\%), Malta (7.0\%), Serbia (7.5\%), Czech Republic (7.5\%), Estonia (7.9\%), Lithuania (8.2\%), Latvia $(8.3 \%)$ [19].

In the post-pandemic period, each country will be faced with the question of finding tools to minimize the negative consequences of pandemics, epidemics and other negative global phenomena. One of the most effective tools is planning and forecasting. Many experts have characterized the pandemic as a war, based on a number of classifications. The experience of waging war allows military specialists to conclude that, all other things being equal, a strategic advantage is gained by the side that has not only a combat plan, but also a plan for logistic support of troops and the production of weapons.

Thus, the COVID-19 pandemic has stimulated interest in planning and forecasting in modern conditions and the use of existing innovations in these processes, as well as the creation of new ones. Based on the logic of state planning and the existing experience of the functioning of the economy [20, 21, 22, 23, 24, 25, 26, 27] and the system of state and municipal administration in a pandemic, the Russian Federation needs to develop a Concept, Forecast and Strategy for countering pandemic and epidemiological challenges and threats, a Plan for the functioning of the Russian Federation in a pandemic and epidemic. In its methodological essence, such a plan can be indicative, i.e. agreed with all 
parties, namely, the state, interested in budget execution and receipt of income, business seeking to receive income and profit, trade unions and citizens interested in maintaining and increasing living standards. It also requires adjustments to previously developed and adopted concepts and strategies.

In the forecasting and planning system that is emerging in the Russian Federation, there is a certain drawback, namely, the procedures for short-term planning on the horizon of 1-3 years have been worked out quite fully, procedures for long-term planning (15-30 years) are being developed and practiced, but between them there is no objectively necessary level of medium-term planning in the form of indicative plans [28]. A number of indicators characterizing the epidemiological situation in the country, regions and cities were tested after the start of quarantine measures, which did not contribute to the selection of the most effective of them.

\section{Conclusion}

In conclusion, the following main conclusions should be drawn. The pandemic of the coronavirus COVID-19 in 2020 not only caused the expansion of the scope of many innovations or the emergence of new ones, but also itself was a kind of Schumpeterian "creative destroyer". And in this regard, in our opinion, requires a rethinking of the theoretical and methodological content of the category "innovation". The pandemic, in our opinion, acted as an objective factor, testifying in favor of expanding the interpretation of innovation not only as a result of human activity, but also the activity of the biosphere, one of the components of which are humans and viruses.

The pandemic acted as a powerful factor of "creative destruction", which caused significant destruction in socio-economic systems. In this aspect, in our opinion, the position of J. Schumpeter remains relevant that outdated industries should not be preserved indefinitely, but it is necessary to prevent collapse and transform chaos into a planned retreat.

The COVID-19 coronavirus pandemic has led to the expansion of digitalization, which is leading to business transformation, the creation of new enterprises, jobs in many industries, the creation and development of a variety of digital platforms. Digital innovation has reduced the magnitude of the economic downturn in many industries and in the socioeconomic system as a whole. Therefore, one of the criteria for the effectiveness of a particular innovation, in our opinion, may be the possibility of ensuring growth in normal and pandemic conditions or a slight decrease in this indicator in pandemic conditions.

The next global innovation, which was provoked by the COVID-19 coronavirus pandemic, is the so-called "coronation" of economic activity, which is the antipode of globalization. Moreover, this innovation is cyclical, each time reviving at a qualitatively new level and basis. The two largest economies in the world (China and the United States) are drifting towards the priority development of their own markets and economic entities. Similar processes will take place in other countries.

The COVID-19 pandemic has updated the issues of planning and forecasting in modern socio-economic systems and the use of existing and new innovations in these processes. In the Russian Federation, it is necessary to develop a Concept, Forecast and Strategy for countering pandemic and epidemiological challenges and threats, a Plan for the functioning of the Russian Federation in a pandemic and epidemic. In its methodological essence, such a plan can be indicative, i.e. agreed with all parties, namely the state, business, trade unions and citizens. It is also necessary to adjust the previously developed and adopted concepts and strategies. 


\section{Acknowledgements}

The work was prepared with the financial support of the RFBR in the framework of the scientific project No. 18-010-00459.

\section{References}

1. OECD Science, Technology and Innovation Outlook 2018. Adapting to Technological and Societal Disruption (Paris, OECD Publishing, 2018)

2. G.G. Onishchenko, V.P. Toporkov, V.Yu. Smolensky, A.V. Toporkov, Infectious Diseases: News. Opinions. Training 1(14), 75 (2016)

3. J.A. Schumpeter, Economic development theory. Capitalism, socialism and democracy (M., EKSMO, 2008)

4. P.M. Gureev, Bulletin of the State University of Management 1, 189 (2016)

5. E.B. Danilkova, Vestnik VSUIT 79(1), 326 (2017) doi: 10.20914 / 2310-1202-2017-1326-331

6. S.Yu. Rumyantseva, E.M. Korostyshevskaya, I.O. Samylov, Innovations 3(233), 36 (2018)

7. M.S. Gusev, Yu.V. Babanova, Bulletin of SUSU. Series "Economics and Management" 10(3), 67 (2016) DOI: 10.14529 / em160309

8. B.G. Ivanovsky, Economic and social problems of Russia 1, 141 (2019)

9. I. Bak, K. Cheba, I. Lacka, European Research Studies Journal XXIII(3), 93 (2020)

10. Ya.V. Trofimova, Innovations 11(217), 57 (2016)

11. A. Tóth, T. Juhász, B. Kálmán, Montenegrin Journal of Economics 16(1), 251 (2020)

12. T. Jałowiec, P. Maśloch, H. Wojtaszek, I. Miciuła, G. Maśloch, European Research Studies Journal XXIII(2), 151 (2020)

13. V.S. Uskov, Economic and Social Changes: Facts, Trends, Forecast 13(1), 70 (2020) DOI: 10.15838 / esc.2020.1.67.4

14. T.V. Luzina, E.A. Dudareva, Azimuth of scientific research: economics and management 8-1(26), 201 (2019)

15. V.Yu. Smolensky, S.K. Udovichenko, V.P. Toporkov, V.V. Kutyrev, Problems of especially dangerous infections 3, 5 (2017)

16. A.I. Prigogine, Innovations: incentives and obstacles (social problems of innovation) (Moscow, Politizdat, 1989)

17. OECD Economic Outlook 2020(1) https://www.oecd-ilibrary.org/docserver/0d1d1e2een.pdf

18. V.I. Vernadsky, Biosphere and Noosphere (M., Iris Press, 2012)

19. Global Economic Outlook of the International Monetary Fund "Prospects for the Development of the World Economy", https://www.imf.org/ru/Publications/WEO/Issues/2020/04/14/ weo-april-2020

20. V. Krolivetskaya, E. Krolivetsky, E3S Web Conf. 135, 05026 (2019) DOI: https://doi.org/10.1051/e3sconf/201913504032

21. A. Evmenov, E. Krolivetsky, S. Krolivetskaya, T. Sorvina, E3S Web Conf. 164, 10036 (2020) DOI: https://doi.org/10.17323/j.jcfr.2073-0438.13.2.2019.104-113

22. D. Radushinsky, A. Radushinskaya, I. Radikov et al., MATEC Web of Conferences 
170, 01043 (2018) DOI: https://doi.org/10.1051/matecconf/201817001043

23. D. Radoushinsky et al., St. Petersburg State Polytechnical University Journal. Economics 5(204), 54 (2015) DOI: https://doi.org/10.5862/JE.228.5

24. D. Radoushinsky, St. Petersburg State Polytechnical University Journal. Economics 5(251), 57 (2016) DOI: 10.5862/JE.251.6

25. D. Radoushinsky, Ural Federal University Bulletin. Economics and Management Series 16(1), 623 (2017) DOI 10.15826/vestnik.2017.16.4.030

26. N.I. Evmenova, E.N. Krolivetskiy, St. Petersburg Economic Journal 1, 15 (2020)

27. E.N. Krolivetskiy, O.A. Sorokin, Bulletin of Education and Science Development of the Russian Academy of Natural Sciences 3, 20 (2017)

28. T.I. Ladykova, Topical issues of indicative planning in conditions of great challenges of the world economy (Yekaterinburg, Institute of Economics, Ural Branch of the Russian Academy of Sciences, 2018) 